\title{
Pengaruh Work-Life Balance dan Flexible Work Arrangement Terhadap Kinerja Karyawati Muslimah Konveksi
}

\author{
Fadhila Saifullah \\ Institut Agama Islam Negeri Kudus \\ fadhilasaifullah22@gmail.com
}

\begin{abstract}
This study aims to determine the effect of work-life balance and flexible work arrangement on employee performance, the type of research used is explanatory research with quantitative approach. Sample taken as many as 35 respondents. Data analysis use descriptive statistical analysis. Based on the results of the analysis showed that the variable work-life balance and flexible work arrangement didn't affect the performance of employees as seen from the results of the $t$ test to get a $t_{\text {count }}$ of -1.258 and sig. of $0.218(p>0.05)$ which shows that there is no influence between work-life balance on employee performance. And the t test results obtained a $t_{\text {count }}$ of 2.625 and a sig. of 0.013 ( $p>0.05)$ which indicates that there is no influence between flexible work arrangement on employee performance. The adjusted $R$ square value is only 0.282 , it shows that the work-life balance and flexible work arrangement have an effect of $28.2 \%$ on the performance of employees and the rest $71.8 \%$ is influenced by other variables not included in this study.
\end{abstract}

Keywords: Work-Life Balance, Flexible Work Arrangement, and Employee Performance.

\begin{abstract}
Abstrak
Penelitian ini bertujuan untuk mengetahui pengaruh work-life balance dan flexible work arrangement terhadap kinerja karyawan. Jenis penenlitian yang digunakan adalah explanatory research dengan pendekatan kuantitatif. Sampel yang diambil sebanyak 35 responden. Analisis data menggunakan analisis statistik deskriptif. Berdasarkan hasil analisis menunjukkan bahwa variabel work-life balance dan flexible work arrangement tidak berpengaruh terhadap kinerja karyawan yang dilihat dari hasil uji t mendapatkan nilai $t_{\text {hitung }}$ sebesar -1.258 dan nilai sig. sebesar 0.218 ( $\mathrm{p}>0.05$ ) yang menunjukkan bahwa tidak ada pengaruh antara Work Life Balance terhadap Kinerja karyawan. Dan pada hasil uji t mendapatkan nilai thitung sebesar 2.625 dan nilai sig. sebesar 0.013 ( $p>0.05$ ) yang menunjukkan bahwa tidak ada pengaruh antara Flexible Work Arrangement terhadap Kinerja Karyawan. Nilai adjusted $R$ square hanya 0.282 , hal tersebut menunjukkan bahwa variabel work-life balance dan Flexible Work Arrangement berpengaruh sebesar 28.2\% terhadap kinerja karyawan dan selebihnya $71.8 \%$ dipengaruhi oleh variabel-variabel lain yang tidak termasuk dalam penelitian ini.
\end{abstract}

Kata Kunci: Worl-Life Balance, Flexible Work Arrangement, dan Kinerja Karyawan.

\section{PENDAHULUAN}

Perempuan telah dilekatkan dengan peran domestik dalam sebuah rumah tangga. Peran domestik perempuan diantaranya mengurus rumah, mengurus anak, memasak, dan sebagainya. Perempuan dianggap tidak mampu berkontribusi diluar rumah sehingga peranannya tidak lebih dari sekedar 
aktivitas didalam rumah. Apabila perempuan bekerja diluar rumah dianggap kurang pantas atau tabu. Sedangkan peran laki-laki berada diranah publik yaitu bertanggung jawab sebagai pencari nafkah bagi keluarga. Oleh sebab itu, perempuan dalam rumah tangga memiliki posisi di bawah pria.

Akan tetapi, seorang istri dalam keluarga memiliki wewenang penuh untuk melakukan seluruh aktivitas dan tindakan supaya tercapainya kesejahteraan keluarga. Apabila belum tercapai kesejahteraan karena suami yang penghasilannya belum mencukupi kebutuhan, pada akhirnya seorang istri akan ikut andil dalam mencari nafkah agar tercapainya kesejahteraan keluarga (Pudjiwati, 1985).

Kota Kudus memiliki filosofi yang dihidupi oleh Sunan Kudus yaitu GusJiGang. Gus berarti bagus, Ji berarti mengaji, Gang berarti berdagang. Dengan adanya filosofi tersebut, Sunan Kudus menuntun masyarakat menjadi orang yang berkepribadian bagus, tekun mengaji, dan mau berdagang/berwirausaha. Dari pembauran lewat sarana perdagangan dan semangat Gusjigang itulah, masyarakat Kudus mengenal dan mampu membaca peluang usaha. Berangkat dari sejarah tersebut, mayoritas masyarakat Kudus menjadi pedagang/pengusaha. Oleh karena itu, para pengusaha yang berada dibidang textile diantaranya pengusaha busana dan tas membuka peluang bekerja kepada ibu-ibu yang memiliki kemampuan menjahit.

Namun, pada kenyataannya pekerjaan dan keluarga sama-sama menjadi beban bagi para pekerja yang mayoritas seorang ibu rumah tangga. Ketika memprioritaskan keluarganya, maka akan berdampak pada menurunnya kinerja mereka. Perempuan yang telah berumah tangga lebih sulit membagi waktunya antara bekerja dan keluarga. Dengan adanya Flexible Work Arrangement diharapkan dapat memberikan peningkatan pada kinerja karyawan. Flexible Work Arrangement merupakan kesempatan pekerja untuk membuat pilihan yang mempengaruhi kapan, dimana, dan untuk berapa lama mereka terlibat dalam tugas yang terkait dengan pekerjaan (Bal \& De Lange, 2014). Para pemilik usaha memberikan pekerjaan kepada ibu rumah tangga untuk dikerjakan dirumah dan ketika pekerjaan telah selesai diantarkan kepada pemilik usaha begitu seterusnya. Dengan cara tersebut diharapkan dapat meningkatkan kinerja mereka karena telah diberikan waktu yang leluasa untuk menyelesaikan pekerjaannya tanpa mengganggu perannya sebagai ibu rumah tangga.

Terkadang Flexible Work Arrangement disalahgunakan oleh karyawan. Karena merasa pekerjaannya diperbolehkan dikerjakan dirumah, kinerjanya pun menurun dan malah lebih fokus melakukan perannya sebagai ibu rumah tangga. Hal tersebut akan berdampak pada pekerjaan yang tidak terselesaikan sesuai dengan waktu yang telah ditentukan. Salah satu faktor yang dapat meningkatkan kembali kinerja karyawan adalah dengan WorkLife Balance. Work-Life Balance ialah sejauh mana individu terikat secara bersama didalam pekerjaan dan keluarga, dan sama-sama puas dengan peran dalam pekerjaan dan dalam keluarganya (Greenhaus, 2003). Dengan kata 
lain, karyawan mampu menyeimbangkan antara pekerjaan dan keluarga secara seimbang.

Hasil penelitian terdahulu yang dilakukan oleh Sri Widati (2019) menunjukkan bahwa Work-Life Balance berpengaruh positif dan signifikan terhadap kinerja pegawai. Kemudian, sesuai penelitian yang dilakukan oleh Ischevell Vialara Saina, Riane Johnly Pio, Wihelmina Rumawas (2016) yang menyatakan bahwa Work-Life Balance dan kompensasi bersama-sama mempengaruhi kinerja karyawan sebesar 55,2\%.

Penelitian juga telah dilakukan oleh Hendrik Pandiangan (2018) yang hasilmya menunjukkan bahwa Flexible Working Arrangement berpegaruh positif terhadap Work-Life Balance. Dari penelitian diatas maka masih dibutuhkan penelitian lebih lanjut tentang validitas hasil dalam mengukur pengaruh Work-Life Balance dan Flexible Working Arrangement terhadap kinerja karyawan sehingga dapat menutupi kekurangan dari penelitian terdahulu.

\section{KAJIAN LITERATUR}

\section{Flexible Working Arrangement}

Flexible Working Arrangement merupakan kesempatan karyawan untuk membuat pilihan yang mempengaruhi kapan, dimana, dan untuk berapa lama mereka terlibat dalam tugas yang terkait dengan pekerjaan (Bal dan De Lange, 2014). Flexible Working Arrangement juga didefinisikan sebagai salah satu spektrum struktur kerja yang mengubah waktu kerja atau tempat kerja selesai dilakukan dengan cara teratur. Aspek dari Flexible Working Arrangement diantaranya tempat kerja dan waktu kerja (Selby dan Wilson 2003). Flexible working dapat menurunkan konflik antara pekerjaan dan keluarga, menurunkan stres kerja yang dapat mempengaruhi kinerja individu dan juga dapat mengakibatkan turnover terutama pada pekerja wanita yang pada akhirnya akan memilih meneruskan tanggung jawab keluarga diibandingkan dengan bertahan pada pekerjaan dan mengabaikan komitmen terhadap keluarga.

Flexible Working Arrangement memiliki indikator (Robbins dan Judge, 2017) yang diantaranya:

a. Flextime, kebijakan perusahaan dimana memungkinkan karyawan untuk dapat memilih jam kerjanya melalui shift yang telah disediakan oleh perusahaan dan dapat memilih kapan harus beristirahat dan beribadah.

b. Pembagian kerja, pengaturan yang memungkinkan dua individu dapat bertukar waktu kerja tetapi tidak mengurangi jatah libur atau jatah cuti.

\section{Work-Life Balance}

Work-Life Balance adalah suatu keadaan dimana seseorang mengalami keterikatan dan kepuasan yang seimbang dalam perannya sebagai pekerja dan didalam keluarganya (Greenhaus, 2003). Komponen dari Work-Life Balance diantaranya :

a. Keseimbangan waktu, merefleksikan jumlah yang sama atau adil dari waktu yang dihabiskan untuk bekerja dan peran keluarga. 
b. Keseimbangan keterlibatan, tingkat keterlibatan psikologis yang sama dalam pekerjaan dan peran keluarga.

c. Keseimbangan kepuasan, tingkat kepuasan yang sama dalam peran pekerjaan dan keluarga.

Dalam mengukur Work-Life Balance yang mengacu pada indikator keseimbangan waktu, keseimbangan keterlibatan, dan keseimbangan kepuasan. Faktor-faktor yang mempengaruhi tercapainya Work-Life Balance diantaranya faktor individu, faktor organisasi, faktor lingkungan sosial, dan faktor-faktor lainnya (Poulose dan Sudarsan, 2014). Dari penjelasan sebelumnya, dapat disimpulkan bahwa pengaruh Work-Life Balance disebabkan oleh berbagai hal diantaranya kepribadian, psychological wellbeing, kecerdasan emosi, jabatan, teknologi, dukungan sosial, dan keluarga.

\section{Kinerja Karyawan}

Kinerja karyawan secara umum merupakan hasil yang dicapai oleh karyawan dalam bekerja yang berlaku untuk suatu pekerjaan tertentu (Robins, 2006). Kinerja dalam definisi lain yaitu konsep yang bersifat universal yang merupakan efektivitas operasional suatu organisasi, bagian organisasi, dan karyawannya berdasarkan standar dan kriteria yang telah ditetapkan sebelumnya (Winardi, 1996). Dari penjelasan tersebut, kinerja karyawan dapat didefinisikan sebagai fungsi hasil interaksi antara kemampuan dan motivasi kerja. Pada dasarnya kinerja karyawan dapat mempengaruhi seberapa banyak karyawan memberikan kontribusi kepada suatu organisasi. Faktor yang dapat mempengaruhi kinerja karyawan dibagi menjadi dua, yaitu faktor intrinsik dan ekstrinsik. Faktor intrinsik diantaranya motivasi, pendidikan, kemmapuan, keterampilan, dan pengetahuan. Kemudian faktor ekstrinsiknya adalah lingkungan kerja, kepemimpinan, hubungan kerja dan gaji.

Komponen dari kinerja karyawan meliputi kemampuan individual, perluasan usaha, dan dukungan organisasional. Kemampuan individu mencakup bakat, minat, dan faktor kepribadian. Usaha meliputi motivasi, etika kerja, kehadiran dan rancangan tugas. Sedangkan dukungan organisasional terdiri atas pelatihan dan pengembangan, peralatan dan teknologi, manajemen, serta rekan kerja (Mathis, 2006).

Terdapat enam karakteristik yang digunakan dalam mengukur kinerja karyawan, diantaranya:

a. Kualitas, tingkatan hasil aktivitas yang dilakukan mendekati sempurna dalam arti menyesuaikan beberapa cara ideal dari penampilan aktivitas ataupun memenuhi tujuan yang diharapkan suatu aktivitas.

b. Kuantitas, banyaknya jumlah atau hasil pekerjaan yang dapat diselesaikan dinyatakan dalam jumlah, unit, dan jumlah siklus aktivitas yang diselesaikan.

c. Ketepatan waktu, tingkat suatu aktivitas diselesaikan pada waktu awal yang diharapkan. 
d. Efektifitas, tingkat penggunaan sumber daya organisasi dimaksimalkan untuk meningkatkan keuntungan atau mengurangi kerugian.

e. Kemandirian, tingkat karyawan dapat melakukan fungsi kerjanya tanpa meminta dukungan atau bimbingan dari pengawas.

f. Komitmen kerja, tingkatan karyawan mempunyai komitmen kerja dengan perusahaan dan tanggung jawab karyawan terhadap perusahaan (John Bernardin, 1993).

\section{Hipotesis}

$\mathrm{H} 1$ = diduga adanya pengaruh yang signifikan pada Flexible Work Arrangement (X1) terhadap Kinerja Karyawan (Y)

$\mathrm{H} 2$ = diduga adanya pengaruh yang signifikan pada Flexible Work Arrangement (X2) terhadap Kinerja Karyawan (Y)

\section{Gambar 1. Model Hipotesis}

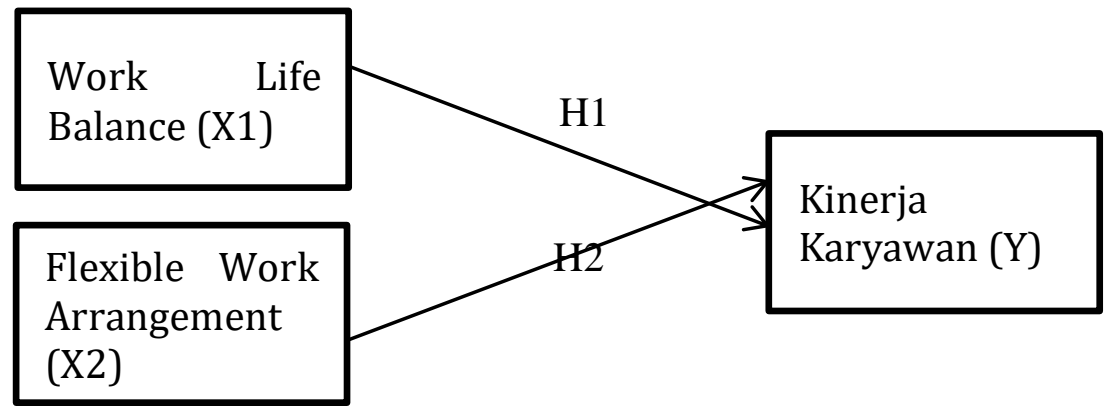

\section{METODE PENELITIAN}

Penelitian ini menggunakan metode pendekatan kuantitatif. Metode kuantitatif ialah penelitian yang datanya berbentuk angka, yang dianalisis menggunakan statistik untuk mengetahui jawaban masalah yang diteliti (Adi, 2004). Metode yang digunakan dalam penelitian ini adalah metode penelitian kuantitatif yang bersifat eksplanatori.

Metode pengambilan sampel yang digunakan adalah non probability sampling dengan menggunakan purposive sampling atau pengambilan sampel bertujuan. Purposive sampling ialah metode yang penentapan sampelnya didasarkan pada kriteria-kriteria tertentu (Suliyanto, 2006). Sampel yang digunakan ialah ibu rumah tangga yang bekerja sebagai penjahit di konveksi wilayah Kabupaten Kudus berjumlah 35 responden.

Metode pengumpulan data menggunakan kuesioner yang berisi pertanyaan atau pernyataan. Skala interval yang digunakan untuk pengukuran data adalah skala likert. Analisis data menggunakan analisis statistik deskriptif dengan cara menggambarkan data yang telah dikumpulkan menjadi sebuah kesimpulan.

\section{PEMBAHASAN}

Berikut hasil analisis data yang telah dilakukan dengan menggunakan SPSS 16.0: 
Tabel 1

Uji Normalitas

One-Sample Kolmogorov-Smirnov Test

\begin{tabular}{lll}
\hline & & $\begin{array}{l}\text { Unstandardized } \\
\text { Residual }\end{array}$ \\
\hline $\mathrm{N}$ & & 35 \\
\hline Normal Parameters $^{\mathrm{a}}$ & Mean & .0000000 \\
\cline { 2 - 3 } & Std. Deviation & 1.66487174 \\
\hline Most Extreme & Absolute & .119 \\
\cline { 2 - 3 } Differences & Positive & .098 \\
\cline { 2 - 3 } & Negative & -.119 \\
\hline Kolmogorov-Smirnov Z & .701 \\
\hline \multicolumn{2}{l}{ Asymp. Sig. (2-tailed) } & .709 \\
\hline a. Test distribution is Normal. \\
\hline
\end{tabular}

Sumber: Data primer diolah, 2019

Berdasarkan dari tabel 1 hasil pengujian menunjukkan bahwa nilai Asymp. Sig. (2-tailed) diperoleh sebesar 0.709 yang artinya lebih dari 0.05 menunjukkan bahwa nilai residual tersebar normal atau diartikan sebagai asumsi normalitas data terpenuhi.

Tabel 2

Uji Multikolonieritas

Coefficients $^{\mathbf{a}}$

\begin{tabular}{|c|c|c|}
\hline \multirow[t]{2}{*}{ Model } & \multicolumn{2}{|c|}{ Collinearity Statistics } \\
\hline & Tolerance & VIF \\
\hline Flexible Work Arrangement & .156 & 6.390 \\
\hline Work-Life Balance & .156 & 6.390 \\
\hline
\end{tabular}

a. Dependent Variable: Kinerja Karyawan

Sumber: Data primer diolah, 2019

Hasil dari pengujian tabel 2 diatas menunjukkan bahwa nilai VIF $<10$, yang artinya uji asumsi multikolenieritas terpenuhi.

Tabel 3

Uji Koefisien Jalur Flexible Work Arrangement terhadap Kinerja Karyawan

Coefficients $^{\mathrm{a}}$

\begin{tabular}{c|c|c|cc}
\hline \multicolumn{1}{c|}{ Variabel } & Beta & thitung & p-value & \\
\hline $\begin{array}{l}\text { Flexible Work } \\
\text { Arrangement }\end{array}$ & .964 & 2.625 & .013 \\
\hline
\end{tabular}

a. Dependent Variable: Kinerja Karyawan 
R square $\left(\mathrm{R}^{2}\right): 0.325$

Sumber: Data primer diolah, 2019

Hasil dari pengujian tabel 3 diatas menunjukkan bahwa koefisien jalur Flexible Work Arrangement terhadap Kinerja Karyawan sebesar 0.964 dengan arah hubungan yang positif yang artinya bahwa meningkatnya Flexible Work Arrangement akan meningkatkan Kinerja Karyawan, hasil uji t mendapatkan nilai $t_{\text {hitung }}$ sebesar 2.625 dan nilai sig. sebesar 0.013 ( $\left.p>0.05\right)$ yang menunjukkan bahwa tidak ada pengaruh antara Flexible Work Arrangement terhadap Kinerja Karyawan.

Tabel 4

Uji Koefisien Jalur Work-Life Balance terhadap Kinerja Karyawan Coefficients $^{\text {a }}$

\begin{tabular}{l|l|l|l}
\hline \multicolumn{1}{c|}{ Variabel } & \multicolumn{1}{|c|}{ Beta } & t hitung & p-value \\
\hline $\begin{array}{l}\text { Work-Life } \\
\text { Balance }\end{array}$ & -.462 & -1.258 & .218 \\
\hline
\end{tabular}

a. Dependent Variable: Kinerja Karyawan

R square (R2) : 0.325

Sumber: Data primer diolah, 2019

Hasil dari pengujian tabel 4 diatas menunjukkan bahwa koefisien jalur Work Life Balance terhadap Kinerja karyawan sebesar -0.462 dengan arah hubungan negatif, yang artinya semakin meningkat Work-Life Balance akan menyebabkan penurunan pada Kinerja Karyawan, hasil uji t mendapatkan nilai thitung sebesar -1.258 dan nilai sig. sebesar 0.218 ( $p>0.05)$ yang menunjukkan bahwa tidak ada pengaruh antara Work Life Balance terhadap Kinerja karyawan.

\section{Tabel 5}

Uji Koefisien Korelasi dan Determinasi

\begin{tabular}{ccccc}
\hline Model & $\mathrm{R}$ & R Square & $\begin{array}{c}\text { Adjusted R } \\
\text { Square }\end{array}$ & Std. Error \\
\hline 1 & $.570^{\mathrm{a}}$ & .325 & .282 & 1.716 \\
\hline
\end{tabular}

Sumber: Data primer diolah, 2019

Hasil pengujian tabel 5 menunjukkan bahwa Adjusted $R$ square sebesar 0.282. hal ini menunjukkan bahwa Work-life balance dan Flexible Work Arrangement berpengaruh sebesar $28.2 \%$ terhadap Kinerja Karyawan. Sedangkan selebihnya dipengaruhi oleh variabel-variabel lain yang tidak termasuk dalam penelitian ini.

\section{SIMPULAN}

Berdasarkan pengujian yang dilakukan dengan menggunakan analisis regresi linier berganda menunjukkan bahwa tidak terdapat pengaruh yang signifikan antara Flexible Work Arrangement terhadap Kinerja Karyawati muslimah konveksi di Kabupaten Kudus. Berdasarkan pengujian yang dilakukan dengan menggunakan analisis regresi linier berganda menunjukkan bahwa tidak terdapat pengaruh yang signifikan antara Work-Life Balance terhadap Kinerja Karyawati muslimah konveksi di Kabupaten Kudus. 


\section{DAFTAR PUSTAKA}

Adi, R. (2004). Metodologi Penelitian Sosial dan Hukum, Jakarta: IND Granit, 2004.

Bal, P. a. (2014). From flexibility human resource management to employee engagement and perceived job performance across the lifespan: A multisample study. Journal of Occupational and Organisational Psychology, Vol 88 (1), 126-154.

Bernardin, H.J. \& Russel, J.E.A. (1993) Human Resource Management an Experiental Approach, Singapore: Mc Graw-Hill Inc.

Greenhaus, J.H., Collins, K.M., dan Shaw, J.D. (2003). The Relation Between Work-Family Balance and Quality of Life, Journal of Vocational Behavior, Vol 63, 510-531, 2003.

Mathis, R.L. \& J.H. Jackson. (2006). Human Resource Management: Manajemen Sumber Daya Manusia, Terjemahan Dian Angelia, Jakarta: Salemba Empat.

Pandiangan, Hendrik. (2018). Flexible Working Arrangement dan Pengaruhnya terhadap Work-Life Balance pada Driver Layanan Jasa Transportasi Online di Kota Yogyakarta, Yogyakarta: Tesis Universitas Sanata Dharma.

Poulose, S., dan Sudarsan. (2014). Work-life balance: A conceptual Review, International Journal of Advances in Management and Economics, Vol $7(1)$.

Saina, Ischevell Vialara., Riane Johnly Pio, Wihelmina Rumawas. (2016). Pengaruh Worklife Balance dan Kompensasi terhadap Kinerja Karyawan pada PT PLN (Persero) Wilayah Suluttenggo Area Manado, Jurnal Administrasi Bisnis, Vol 4 (3).

Sajogyo, Pudjiwati. (1985). Peranan Wanita dalam Perkembangan Masyarakat Desa, Jakarta: CV Rajawali, 1985.

Selby, C., dan Wilson, F. (2003). Flexible Working Handbook.

Stephen P. Robbins. (2006). Perilaku Organisasi edisi kesepuluh, alih bahasa, Jakarta: PT. Indeks Kelompok Gramedia.

Suliyanto. (2006). Metode Riset Bisnis, Edisi Pertama, Yogyakarta: Penerbit Andi Yogyakarta.

Widiati, Sri, (2019). Pengaruh Work Life Balance terhadap Kinerja Pegawai dengan Kepuasan Kerja sebagai Variabel Intervening pada Badan Inspektorat Kabupaten Konawe, Jurnal Manajemen Lakidende Economic \& Business, Vol. 1(1). 1-8. 